\title{
Desempenho de enfermeiras na coleta de material cervico- uterino para exame de Papanicolaou*
}

\author{
Performance of nurses in gathering material for Pap smear test
}

Desempeño de enfermeras en la recolección de material cérvico uterino para examen de Papanicolaou

\author{
Nancy Costa de Oliveira ${ }^{1}$, Escolástica Rejane Ferreira Moura ${ }^{2}$, Maria Albertina \\ Rocha Diógenes ${ }^{3}$
}

\begin{abstract}
RESUMO
Objetivos: Verificar conhecimento e prática de enfermeiras na coleta de material cérvico-uterino, identificar disponibilidade de materiais para realização da coleta e conferir adequabilidade da lâmina. Métodos: Estudo transversal, de campo, realizado de agosto a outubro de 2006, com 21 enfermeiras. Conhecimento foi investigado por questionário; técnica de coleta e materiais foram pesquisados por observação; adequabilidade das lâminas foi verificada nos laudos laboratoriais. Resultados: Dezessete enfermeiras se auto-avaliaram seguras para realizar o exame; duas investigaram esvaziamento da bexiga; quatro explicaram o procedimento; nenhuma indagou uso de duchas, abstinência sexual e sangramento intermenstrual; duas não usaram espátula corretamente e duas consideraram desnecessária a coleta da endocérvice; duas coletas levaram tempo excessivo para fixação. Espéculos e pinças Cherron foram insuficientes; 63(100\%) das lâminas estavam adequadas. Conclusão: Há déficit de conhecimento e de técnica, insuficiência de materiais, e apesar das falhas observadas na coleta, 100\% dos laudos conferiram adequabilidade às lâminas.

Descritores: Esfregaço vaginal; Neoplasias do colo do útero; Avaliação de desempenho; Conhecimentos, atitudes e prática em saúde
\end{abstract}

\begin{abstract}
Objectives: Verify nurses' knowledge and practice to material uterine cervical, to identify availability of material of collection and to verify suitability of the smears. Methods: Transversal study, at service, was carried from August to October 2006, with 21 nurses. Knowledge was investigated through questionnaire; collection technique and material were researched through observation; suitability of the smears was verified in the lab reports. Results: Seventeen nurses evaluated themselves security to carry through the examination; two had asked about emptiness of bladder and four had explained procedure; none inquired using a shower, sexual abstinence and bleed intermenstrual; two had left to use of spatula correctly and two had considered unnecessary endocervix collection; two collections the time for fixation was excessive. Speculums and Cherron clamps had been insufficient; $63(100 \%)$ blades were adjusted. Conclusion: It has been detected deficit of knowledge and technique, insufficiency of materials, and although the imperfections observed in the collection, $100 \%$ of the findings had conferred adequateness to the blades.
\end{abstract}

Keywords: Vaginal smears; Uterine cervical neoplasms; Employee performance appraisal; Health knowledge, attitudes, practice

\section{RESUMEN}

Objetivos: Verificar conocimiento y práctica de enfermeras en colecta de material del cuello uterino, identificar disponibilidad de materiales para realización de coleta y averiguar adecuación de lámina. Metodos: Estudio transversal, de campo, realizado de agosto a octubre de 2006, con 21 enfermeras. Conocimiento fue investigado por cuestionario; técnica de colecta y materiales fueron investigados por observación; adecuación de láminas fue verificada en laudos laboratorillos. Resultados: Diecisiete enfermeras se evaluaron seguridad en la examinación; dos preguntaron por el vacío de vejiga; cuatro explicaron el procedimiento; ninguno preguntó sobre usar ducha, abstinencia sexual y sangría intermenstrual; dos no utilizaron espátula correctamente y dos habían considerado innecesario colección del endocervice; dos colecciones llevó tiempo excesivo para fijación. Espéculos y pinzas Cherron fueron escasas; 63 (100\%) láminas fueron satisfactorias. Conclusion: Ha déficit del conocimiento y técnica, escasez de materiales, y aunque de las imperfecciones observadas en colección, 100\% de las láminas tuvieran adecuación conferida. Descriptores: Frotis vaginal; Neoplasias del cuello uterino, Evaluación de desempeño; Conocimientos, actitudes y práctica en salud

\footnotetext{
* Trabalho extraído da Dissertação de Mestrado apresentada ao Programa de Pós-Graduação em Enfermagem da Universidade Federal do Ceará - UFC Fortaleza (CE), Brasil. Financiada pelo CNPq - Seleção Pública de propostas sobre Pesquisas Avaliativas em Atenção Básica à Saúde.

${ }^{1}$ Mestre em Enfermagem. Enfermeira Programa Saúde da Família da Prefeitura Municipal de Fortaleza. - Fortaleza (CE), Brasil.

${ }^{2}$ Doutora em Enfermagem. Livre-docente da Universidade Federal do Ceará - UFC. - Fortaleza (CE), Brasil.

${ }^{3}$ Doutora em Enfermagem. Livre- docente da Universidade de Fortaleza - UNIFOR - Fortaleza (CE), Brasil.
} 


\section{INTRODUÇÃO}

No Brasil, a mortalidade por câncer de colo uterino (CCU) ainda é elevada, porém o número de casos, atualmente, é bem menor do que costumava ser antes da realização do "exame de prevenção" pela técnica de Papanicolaou ${ }^{(1)}$.

Estimativa do Instituto Nacional de Câncer para 2008 determinou a ocorrência de 18.680 casos novos de câncer de colo de útero no Brasil, sugerindo um risco de 20 casos para cada 100.000 mulheres. Destes, 770 casos ocorreriam no Ceará (17,80/100.000 mulheres), sendo esperados 240 casos na capital e 530 no interior ${ }^{(2)}$.

Métodos alternativos e/ou tecnologias avançadas para o rastreamento do CCU vem sendo pesquisadas, como a Inspeção Visual com Ácido Acético (IVA) e os testes de captura híbrida para detecção do papilomavírus humano (HPV). A IVA vem sendo utilizada em países em desenvolvimento por ser um método simples, requerer infraestrutura mínima e oferecer resultado imediato. Já a captura híbrida (CH II), é um procedimento de hibridização molecular, de rápido processamento e leitura confiável, capaz de detectar 18 tipos de HPV divididos em grupos de alto e baixo risco de oncogenicidade ${ }^{(3)}$.

O exame de prevenção pela técnica de Papanicolaou ou citologia oncótica, consiste na coleta e análise de material celular da cérvice uterina que permite, a detecção de lesões precursoras e da doença em estágios iniciais, antes mesmo do aparecimento dos sintomas, vem sendo utilizado largamente, desde sua descoberta, em 1943. É um exame bastante aceito pela comunidade científica e de relevância para a Saúde Pública, por ser de baixo custo e fácil realização( ${ }^{(4)}$.

O Brasil foi um dos primeiros países do mundo a utilizar o exame de Papanicolaou, que, até hoje, é tido como suporte principal no controle do CCU. Países como América do Norte, Finlândia, Dinamarca, Holanda, Noruega e Reino Unido utilizam o teste em programas de rastreamento. A Província da Colúmbia Britânica do Canadá possui um dos programas de rastreamento mais bem- sucedidos do mundo. De maneira geral, o sucesso desses programas está relacionado a fatores, como cobertura efetiva da população de risco, qualidade na coleta e interpretação do material, tratamento e acompanhamento adequados ${ }^{(1)}$.

O exame de Papanicolaou quando ofertado de acordo com o padrão de qualidade, abrangência de $80 \%$ ou mais da população e tratamento adequado é capaz de reduzir o aparecimento de $90 \%$ dos casos de câncer invasor ${ }^{(5)}$. Apesar dos benefícios do exame preventivo, falhas na coleta de material, preparo, conservação e interpretação das lâminas podem prejudicar o controle do CCU. Nessas atividades, o trabalho manual vai desde o momento da coleta do material até o laudo emitido pelo laboratório, caracterizando o desempenho profissional nessas atividades como extremamente relevante, justificando estudos na área.

Problemas relacionados com a coleta de material podem e devem ser sempre investigados com o objetivo de serem corrigidos. A avaliação das amostras obtidas é de fundamental importância para se definir programas de reeducação para coleta e preparo do material pelos profissionais envolvidos ${ }^{(4)}$.

Em sua maioria, o exame de prevenção é marcado na rede básica de saúde pelas equipes do Programa de Saúde da Família PSF e, particularmente, pelas enfermeiras questionamos: essas profissionais têm conhecimento satisfatório sobre a coleta de material para o exame de Papanicolaou e o realizam adequadamente? As Unidades Básicas de Saúde (UBS) dispõem de recursos materiais necessários para realização da coleta? Os laudos laboratoriais confirmam à adequabilidade do material coletado por esses profissionais?

Diante do exposto, decidimos pela realização do presente estudo que teve como objetivos verificar o conhecimento e a prática de enfermeiras do PSF com relação à coleta de material cérvico-uterino para o exame de Papanicolaou; identificar a disponibilidade de recursos materiais necessários para realização da coleta e averiguar a adequabilidade da lâmina, segundo o laudo laboratorial.

\section{MÉTODOS}

Estudo transversal, de campo, realizado no município de Maranguape-CE, de agosto a outubro de 2006, no qual participaram 21 enfermeiras do PSF, já que todas realizavam o exame preventivo do CCU. No período do estudo, o município contava com 21 equipes cadastradas no Programa Saúde da Família e em franca atividade, sendo cada uma composta por uma enfermeira, um médico, um auxiliar de enfermagem e de seis a dez agentes comunitários de saúde. Os dados sobre o perfil profissional das enfermeiras e o conhecimento teórico destas sobre a realização da coleta de material foram levantados por meio de questionário. A técnica da coleta citológica e a disponibilidade dos recursos materiais para este fim foram pesquisadas através da observação estruturada participante direta, guiada pelo Instrumento de Reconhecimento da Qualidade (IRQ). Já a verificação de adequabilidade das lâminas foi realizada mediante leitura dos resultados dos exames emitidos pelo laboratório.

O IRQ é parte da "Metodologia de Melhoria da Qualidade" elaborada pela Secretaria da Saúde do Ceará em parceria com o Program for International Education in Reproductive Health, Management Sciences for Health e o Center for Communication on Programs ${ }^{(6)}$. O referido instrumento representa um padrão para a realização adequada da coleta de material para o exame de Papanicolaou, formatado passo a passo, permitindo registrar em cada 
critério observado uma das opções: $\operatorname{Sim}(\mathrm{S})$; Não $(\mathrm{N})$; ou Não se aplica (NA), conforme o desempenho profissional apresentado. O "NA" é utilizado nas situações em que o critério é desnecessário ao atendimento daquela cliente.

Para se evitar a reatividade manifesta pela presença do observador, adotamos o critério recomendado por autoras que consiste em observar três procedimentos por sujeito da pesquisa, fato que resultou na observação da confecção de 63 lâminas $^{(7)}$. A prática de cada enfermeira foi analisada por meio de cada etapa da coleta, sendo considerada satisfatória a etapa que obtivesse três respostas Sim (S) ou Não se aplica (NA)().

Os resultados dos exames citopatológicos foram acessados no banco de dados disponível na Coordenação da Atenção Básica da Secretaria de Saúde do município. Ressaltamos que, durante a etapa de observação das coletas, anotamos no IRQ o número do prontuário da usuária, a data e o número de ordem, de forma a identificar os resultados interessados posteriormente. Assim, os resultados contendo o número de ordem referente à pesquisa puderam ser selecionados facilmente.

A pesquisa foi realizada após a aprovação do Comitê de Ética em Pesquisa da Universidade Federal do Ceará, conforme Parecer no 383/2006 e assinatura do Termo de Consentimento Livre e Esclarecido e seguiu as recomendações da Resolução 196/96 do Conselho Nacional de Saúde, que trata de pesquisas envolvendo seres humanos ${ }^{(8)}$.

\section{RESULTADOS}

Os resultados foram organizados quanto ao perfil profissional das enfermeiras, conhecimento e prática desse grupo sobre a coleta de material para o exame de Papanicolaou, disponibilidade dos recursos materiais para realização da coleta e adequabilidade das lâminas, conforme laudo laboratorial.

As participantes, todas do sexo feminino, apresentaram tempo de formadas que variou de 1 a 25 anos, predominando o tempo de 9 a 11 anos; a média de atuação em realização do exame de prevenção do CCU foi de 8 anos; 14 enfermeiras $(66,7 \%)$ não tiveram prática nessa área durante a graduação; e 11 (52,4\%) não receberam nenhum treinamento como oportunidade de educação continuada. Assim, 16 (76,2\%) afirmaram ter acesso a manual de normas técnicas sobre a temática, oferecido pelo Ministério da Saúde. Esse aspecto mobilizou as enfermeiras para a autoaprendizagem, levando 17 (81\%) a autoavaliarem-se como seguras para realizar a coleta. Quatro $(19 \%)$ autoavaliaram-se como inseguras para realização do procedimento, destacando

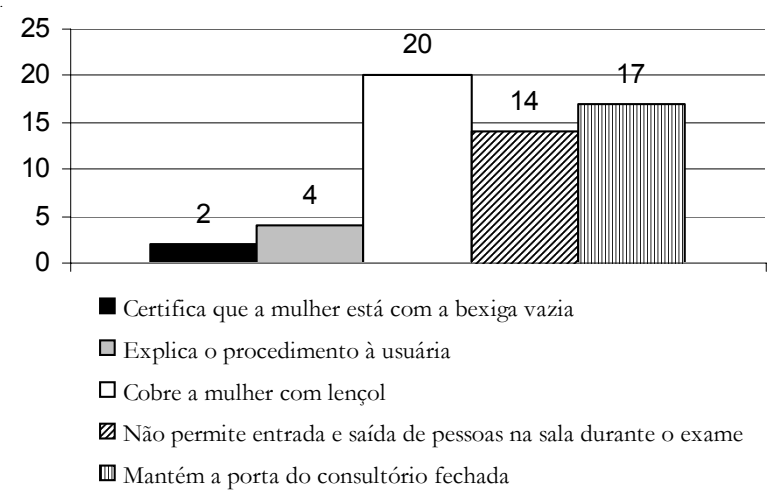

Figura 1 - Enfermeiras segundo oferta de conforto e privacidade à mulher durante exame preventivo do CCU. Maranguape-CE, ago./out., 2006

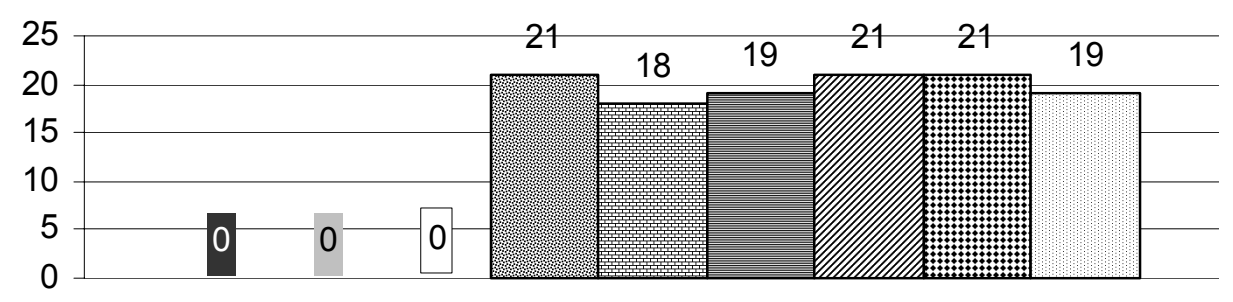

- Certifica abstinencia sexual da mulher nas últimas $48 \mathrm{~h}$

$\square$ Certifica ausência de ducha e medicamento intravaginal nas últimas $48 \mathrm{~h}$

$\square$ Investiga sangramento fora do fluxo menstrual

图 Introduz o espéculo sem lubrificante

園 Coleta material da ectocérvice com a ponta denteada da espátula de Ayre fazendo rotação de $360^{\circ}$

国 Coleta material da endocérvice com escova Campos da Paz

Realiza o esfregaço em lâmina única

Imerge a lâmina em álcool absoluto ou aplica spray fixador

Retira o espéculo adequadamente

Figura 2 - Enfermeiras segundo certificação das condições ideais das mulheres para exame de Papanicolaou e realização da técnica de coleta de material cérvico-uterino. Maranguape-CE, ago./out., 2006. 
dificuldades quanto ao manejo do espéculo, descrição do colo uterino e preparação do esfregaço.

$\mathrm{O}$ conhecimento teórico das enfermeiras quanto a obtenção de lâmina adequada para o exame de Papanicolaou revelou: adequabilidade do esfregaço (18), enfatizando o material bem disposto na lâmina (7), material suficiente (6), ausência de sangue no esfregaço (5) e identificação correta da lâmina (11).

Quanto ao local adequado para a coleta citológica, as enfermeiras citaram: endocérvice e ectocérvice com ênfase na Junção Escamo Colunar (JEC) (10); ectocérvice, endocérvice e fundo de saco (5); endocérvice e fundo de $\operatorname{saco}(1)$.

Os resultados sobre a prática das enfermeiras na coleta de material para o exame de Papanicolaou foram organizados sob o ponto de vista da oferta de conforto e privacidade à mulher (Figura 1) e técnica de coleta citológica (Figura 2), contemplando as etapas recomendadas no IRQ.

À exceção do espéculo, os demais recursos materiais para realização do exame de prevenção estiveram disponíveis para as 21 enfermeiras pesquisadas; 19 enfermeiras $(90,4 \%)$ não dispunham de espéculos nos três tamanhos (pequeno, médio e grande), dificultando uma escolha adequada à condição perineal das usuárias e, impedindo, inclusive, a coleta em determinadas situações ou gerando desconforto nas usuárias, pela tentativa de evitar a cliente retornar sem realizar o exame.

De acordo com os laudos laboratoriais, as 63 lâminas coletadas $(100 \%)$ durante a pesquisa foram satisfatórias, embora tenham sido observados aspectos que infringiram a técnica padronizada no IRQ, como morosidade entre a coleta do material e sua fixação; coleta abrasiva resultando em sangramento do colo e, consequentemente, em esfregaço com presença de sangue e esfregaço vigoroso.

\section{DISCUSSÃO}

O fato das enfermeiras pesquisadas serem do sexo feminino pode favorecer a interação com as clientes, pois há por parte das usuárias uma preferência pelo profissional do sexo feminino, o que pode ser justificado por uma conotação de cumplicidade entre seres semelhantes ${ }^{(9)}$. Pesquisa realizada no Ceará constatou que mulheres ainda apresentam resistência para realizar exame ginecológico com profissional do sexo masculino, documentando as seguintes percepções que comprovam essa assertiva: [...] Durante o exame, fiquei toda me tremendo, morrendo de vergonha porque foi homem [...]; outra usuária ressaltou - [...] Senti-me diferente porque era mulher [referindose à profissional], se fosse homem era mais ruim $[. . .]^{(10)}$.

O largo tempo de formadas e de realização do exame de prevenção do grupo estudado poderá estar associado ao desempenho satisfatório na coleta citológica, mas há de se destacar a lacuna deixada na formação da graduação e da educação continuada dessas enfermeiras que procuram superação na autoaprendizagem embasada em manuais técnicos enviados pelo Ministério da Saúde, estratégia digna de reconhecimento.

O conjunto das enfermeiras apresentou conteúdos corretos para obtenção de uma coleta citológica adequada, realizando observações quanto ao esfregaço adequado (material bem disposto, suficiência de material, ausência de sangue) e identificação da lâmina.

Uma lâmina, com material citológico do colo uterino, considerada adequada deve conter três tipos de epitélio: o pavimentoso estratificado (localizado na parte externa do colo uterino, em contato com a vagina); cilíndrico ou glandular (encontrado na endocérvice); e o metaplásico (localizado na JEC). A presença de células cilíndricas endocervicais no esfregaço é indispensável para avaliação citopatológica segura, reduzindo a possibilidade de falsos-negativos ${ }^{(1)}$.

O Ministério da Saúde desaconselha a coleta de material do fundo de saco por ser de baixa qualidade para o diagnóstico oncótico ${ }^{(5)}$. O conhecimento anátomofisiológico do colo uterino também é importante, pois alterações podem ocorrer na localização da JEC que, na infância e pós-menopausa se situam, geralmente, para dentro do canal cervical; e na menacme, em razão da ação estrogênica situa-se no orifício externo ou para fora deste, fenômeno denominado de ectopia ou eversão ${ }^{(1)}$.

Nesse contexto, a maioria das enfermeiras apontou a ectocérvice e a endocérvice, como locais adequados para a coleta citológica, o que é satisfatório, pois a visão de uma coleta na endocérvice e ectocérvice, com um apanhado da junção escamocolunar (JEC) é o recomendado. Na JEC, localizam-se mais de $90 \%$ dos casos de carcinoma cervical ${ }^{(1)}$. Portanto, as enfermeiras, em geral, demonstraram conhecimento apropriado para proporcionar esse desfecho.

O item conforto da mulher durante o exame preventivo (Figura 1) pode ser proporcionado pela simples atitude de certificar-se de que a usuária está com a bexiga vazia e explicar-lhe os passos do procedimento. A bexiga vazia relaxa a musculatura perineal, amenizando o desconforto. Por outro lado, a contratilidade da musculatura pélvica, vaginal e perineal dificultam a introdução do espéculo, causando tensão, desconforto e dor, o que é superado quando o profissional conversa com a usuária sobre as etapas da coleta ${ }^{(11)}$.

No grupo estudado, poucas enfermeiras tiveram esses cuidados, resultado já detectado também em pesquisa com 11 enfermeiras de municípios do Ceará, nenhuma investigou o esvaziamento da bexiga antes do exame, e só quatro explicaram o procedimento ${ }^{(12)}$. Estudo que observou a preparação de 21 mulheres para realizar o exame de Papanicolaou mostrou que apenas 13 receberam orientação 
quanto ao procedimento que iria ser realizado ${ }^{(13)}$.

Pesquisa realizada em Fortaleza-CE mostrou que, além do medo, as mulheres ficam inseguras antes, durante e após a realização do exame de prevenção ${ }^{(14)}$. Faz-se necessário, portanto, maior interação entre enfermeiras e usuárias, de modo a suplantar o tecnicismo e oferecer cuidados embasados no saber biológico, mas também psicológico e cultural. A principal atitude para o sucesso dos profissionais da área de saúde é a compreensão do ser humano e de suas necessidades, associadas à capacidade de comunicação ${ }^{(15)}$.

A privacidade da usuária durante o exame (Figura 1) pode ser promovida, cobrindo-a adequadamente com um lençol, evitando o entra e sai de pessoas no ambiente em que é realizado o exame e mantendo a porta do consultório fechada. Apesar da maioria das enfermeiras ter tido o cuidado de utilizar o lençol durante o exame, destaca-se que este é único para todas as usuárias, a incluir, o que cobre a mesa ginecológica. Uma das enfermeiras orientava as clientes a trazer uma toalha de casa para proteger a mesa ginecológica durante o procedimento. O ideal seria que aventais ou camisolas e lençóis fossem descartáveis. Caso sejam reutilizados, devem ser encaminhados à rouparia para lavagem, segundo rotina da $(\mathrm{UBS})^{(5)}$.

A maioria das enfermeiras evitou que as pessoas entrassem e saíssem durante o atendimento e mantiveram a porta do consultório fechada. O Ministério da Saúde enfatiza que $\mathrm{o}$ atendimento à mulher deve ser individual, privativo, garantindo a presença do/a acompanhante, quando ela assim o desejar ${ }^{(5)}$.

$\mathrm{Na}$ prática diária, vê-se que essas barreiras persistem mesmo com a lógica que norteia a Estratégia Saúde da Família. Percebe-se que, na cultura das comunidades, estão presentes o medo, os tabus e os preconceitos relacionados ao exame de prevenção do CCU. Ainda ocorrem casos em que o homem não permite que sua parceira busque este tipo de serviço ou, ainda, não colabora com o tratamento quando requerido.

Os fatores evitáveis são muitos e podem interferir no resultado da coleta citológica, como relação sexual nas 48 horas que antecedem ao exame, resquícios de medicamentos no canal vaginal e presença de esperma no esfregaço ${ }^{(11)}$. $\mathrm{O}$ uso de ducha ou medicamento local nas 48 horas, antes da coleta elimina depósitos celulares e impede a obtenção de amostra adequada. A instilação de medicações vaginais no mesmo período dificulta a interpretação citológica. A aplicação tópica de antibióticos promove uma descamação mais rápida de células, sendo indicado, portanto, que a coleta seja adiada por, pelo menos, um mês.

Apesar de constituir aspectos importantes à qualidade da lâmina, nenhuma das enfermeiras pesquisadas abordou as usuárias com questionamentos dirigidos para tais eventos. Mas não questionaram a respeito do sangramento fora do período menstrual, quando se torna oportuno afirmar que a coleta de uma amostra durante a menstruação ou sangramento transvaginal de outra natureza é inadequada porque o fluxo sangüíneo carreia as células do colo. O ideal é colher a amostra cinco a seis dias antes da menstruação ou uma semana após, porém o sangramento fora do período menstrual deverá ser pesquisado mesmo com a possibilidade de não se obter a melhor coleta, pois é uma condição que precisa ser esclarecida com brevidade e guarda forte relação com o CCU e do endométrio. Caso haja presença de sangue no esfregaço, gotas de ácido acético a $2 \%$ podem ser adicionadas à solução fixadora a fim de limpar a lâmina por hemólise, melhorando a qualidade desta para a leitura ${ }^{(1)}$.

De acordo com o Instituto de Prevenção do Câncer, a técnica da coleta citológica deve ser iniciada pela visualização da vagina e do colo uterino mediante utilização do espéculo sem lubrificante, embora algumas gotas de soro fisiológico a $0,9 \%$ possam ser utilizadas para este fim frente às dificuldades de introdução do instrumento na vagina ${ }^{(16)}$. É recomendado, também, umedecer o espéculo com água morna que, além de facilitar sua introdução, proporciona conforto à usuária ${ }^{(16)}$. O IPC segue descrevendo distinguir a cérvice uterina, coletando material da ectocérvice e da endocérvice. A coleta da ectocérvice é feita com a espátula de Ayre, introduzindo seu braço alongado no canal endocervical, com leveza, para que a parte côncava apliquese na mucosa da ectocérvice, exercendo certa pressão e fazendo uma rotação de $360^{\circ}$, para raspar toda a superfície da mucosa cervical. A coleta da endocérvice deve ser feita com escova endocervical (Campos da Paz), que é introduzida no canal endocervical, fazendo um movimento giratório de $180^{\circ}$ a $360^{\circ}$, evitando-se movimentos repetitivos para não sangrar. Para disponibilizar o material na lâmina, deve-se, inicialmente, colher o material da ectocérvice e, posteriormente, colher da endocérvice. Espalhar o material em fina camada sobre a lâmina e de forma rápida para evitar dessecamento. A seguir, proceder com o processo de fixação da lâmina. Mediante o exposto, a técnica da coleta citológica propriamente dita foi executada plenamente pela maioria das enfermeiras, a exceção de três $(14,3 \%)$ que não utilizaram a espátula de Ayre corretamente, duas $(9,5 \%)$ que não usaram a escova, e duas $(9,5 \%)$ que não retiraram o espéculo adequadamente.

Três enfermeiras não utilizaram a parte denteada da espátula ao coletar material da ectocérvice, o que reduz as chances de realizar um raspado de diâmetro esperado. O correto é introduzir a extremidade mais longa da espátula no óstio do colo, girando $360^{\circ}$, tendo o cuidado de incluir a zona de transformação e a junção escamocolunar, quando visualizada. Aconselha-se realizar primeiro essa coleta para evitar contaminação da lâmina com sangue que, às vezes, aparece após o uso da escova Campos da Paz ${ }^{(1)}$. 
As duas enfermeiras que não realizaram a coleta da endocérvice com a escova Campos da Paz justificaram, como sendo desnecessária porque já haviam realizado a coleta com a espátula sobre o que discordamos. Em se tratando de evidências, uma revisão analisando 28 estudos randomizados, quase randomizados e pareados, com 85.000 pacientes, concluiu que o uso combinado da espátula de Ayre com a escova cervical obtém melhores resultados para o esfregaço do que seu uso isolado ${ }^{(17)}$.

O preparo dos esfregaços em lâmina única, método adotado por todas as enfermeiras desse estudo, é baseado na afirmativa de que este é tão eficaz quanto o método de dupla lâmina, além das vantagens de reduzir os custos e o tempo do trabalho no laboratório ${ }^{(1)}$.

No município estudado, uma realidade é a utilização de um tubo único para colocar várias lâminas de pacientes diferentes. O fato não condiz com a orientação do Ministério da Saúde que desaconselha o acondicionamento e transporte de várias lâminas em um mesmo recipiente ${ }^{(1)}$. Outro aspecto observado, embora de ausente no IRQ, foi o tempo que a lâmina preparada fica exposta no meio ambiente, pois esta deve ser imersa no fixador, imediatamente, a fim de evitar que as células ressequem, vindo a interferir na coloração nuclear e na interpretação citológica ${ }^{(16)}$.

Em duas coletas citológicas, observou-se que o tempo para colocar a lâmina no tubo ultrapassou os 15 segundos preconizados pelo Ministério da Saúde, além de um ventilador estar direcionado para a lâmina, expondo-a ao risco de dessecamento, porém, mesmo assim, o laudo laboratorial não mencionou dessecamento das respectivas lâminas. Apesar dessa contradição à literatura pertinente, o caso foi observado em apenas dois eventos, o que não fornece subsídio para qualquer inferência, mantendo-se os profissionais que realizam coleta a orientação de fixar a lâmina no tempo recomendado.

Outro fato comum foi o vigor desnecessário empregado durante a confecção dos esfregaços, situação em que se presumia haver destruição celular e, consequentemente, adequabilidade insatisfatória da amostra, porém, este aspecto não foi evidenciado nos laudos laboratoriais.

A retirada do espéculo feita de forma inadequada por uma das enfermeiras foi atribuída ao pinçamento do colo uterino, provocando desconforto à usuária. O espéculo deve ser retirado com o mesmo cuidado tido durante sua introduçãoevitando prender o colo entre as "abas" do instrumental, causando incômodo à paciente. Sua retirada aberta causaria dor e traumatismo uretral.

Para a realização da coleta citológica adequada, a enfermeira deverá assegurar-se de todo o material necessário, ou seja, pinça Cherron, espéculos nos três tamanhos (1, 2, 3), foco móvel com haste flexível, espátula de Ayre, luvas de procedimento, escovinha tipo Campos da Paz, porta lâminas contendo álcool etílico a $96 \%$, algodão, gaze esterilizada ou submetida à desinfecção de alto nível, lápis grafite ou preto $\mathrm{n}^{\circ} 2$, formulário de requisição do exame citopatológico, borracha e lâmina de vidro com extremidade fosca para microscopia ${ }^{(6)}$. Os referidos materiais encontravam-se à disposição das enfermeiras, a exceção do espéculo em suas variações de tamanho, porém a regularidade de suprimento mostrouse questionável. Em duas oportunidades, o atendimento às mulheres foi cancelado pela falta de instrumentais (pinça Cherron e espéculo), material que vem da sede do município onde é reprocessado e por dificuldades logísticas acaba faltando. Outra enfermeira cancelou os exames de prevenção duas vezes consecutivas pela falta de formulário de requisição do exame citopatológico. Chamou também a atenção o uso de "copinhos para coleta de escarro", como recipiente para ácido acético e lugol utilizados no exame. A profissional utilizava dois copinhos para cada atendimento, caracterizando desperdício e, posterior, falta desse recurso para o exame ao qual se destina.

É preciso, portanto, que a logística desses recursos seja redimensionada, pois cada mulher não atendida por falta de materiais poderá gerar baixa credibilidade ao serviço. Na perspectiva das enfermeiras, pode ocasionar baixo interesse e desgaste emocional, uma vez que recebem toda a carga de reação das pessoas não assistidas.

Em relação à adequabilidade das amostras coletadas, estas são classificadas em satisfatória ou insatisfatórias. No caso da amostra insatisfatória para avaliação oncótica pode ser por causa do: material acelular ou hipocelular $(<10 \%$ do esfregaço) e leitura prejudicada $(>75 \%$ do esfregaço) por presença de: sangue, piócitos, artefatos de dessecamento, contaminantes externos, intensa superposição celular e outros. É considerada satisfatória a amostra que apresente células em quantidade representativa, bem distribuída, fixada e corada de tal modo que a visualização permita uma conclusão diagnóstica. A disposição em um sistema binário (satisfatório $\mathrm{x}$ insatisfatório) melhor caracteriza a visão microscópica da colheita ${ }^{(1)}$. Mesmo com as poucas falhas cometidas na coleta e preparo das 63 lâminas estudadas, nenhuma foi considerada inadequada conforme o laudo laboratorial. A realidade detectada em Maranguape parece bem particular. Estudos realizados em Santa Catarina e Baturité-CE, por exemplo, revelaram elevado percentual de lâminas com limitação para leitura, relacionada a erros na técnica de coleta e coleta em mulheres com processos inflamatórios agudos ${ }^{(12,18)}$.

Assim, ressaltamos a importância de manter o rigor padronizado na literatura para garantir uma lâmina adequada. Mas, questionamos se determinadas recomendações podem estar sendo estabelecidas de forma excessiva, podendo ocasionar oportunidades perdidas na realização do exame de prevenção, como no caso da presença de sangue na lâmina em que mulheres são orientadas a retornarem posteriormente, 
quando a coleta será possível. Particularmente, nesse caso, destacamos a importância da coleta citológica, visto que sangramentos fora do fluxo menstrual ou pós-coito é sugestivo de $\mathrm{CCU}^{(19)}$.

\section{CONCLUSÃO}

O estudo sinaliza para a necessidade das enfermeiras pesquisadas e as que atuam nessa área do cuidado, proporcionarem melhor conforto e privacidade às mulheres, por ocasião do exame de prevenção. Atitudes simples e humanizadoras, como as de certificar-se se a usuária esvaziou a bexiga e orientá-la sobre as etapas da coleta, tornando-a coparticipe do procedimento, devem ser adotadas. Esse desfecho proporcionará não só a fiel adesão dessa usuária ao exame, como por seu intermédio, estará se formando uma agente de multiplicação favorável ao exame, capaz de mobilizar outras mulheres para esse fim. Este deve ser fortalecido pela garantia de privacidade da mulher durante sua realização.

A técnica da coleta propriamente dita foi considerada

\section{REFERÊNCIAS}

1. Brasil. Ministério da Saúde. Instituto Nacional de Câncer. Ações de enfermagem para o controle do câncer: uma proposta de integração ensino-serviço. 2a. ed. Rio de Janeiro: INCA; 2002.

2. Brasil. Ministério da Saúde. Instituto Nacional do Câncer. Coordenação de Prevenção e Vigilância. Estimativa 2006: incidência de câncer no Brasil. Rio de Janeiro: INCA; 2005.

3. Gontijo RC, Derchain SFM, Roteli-Martins C, Sarian LOZ, Bragança JF, Zeferino LC, Silva SM. Avaliação de métodos alternativos à citologia no rastreamento de lesões cervicais: detecção de DNA-HPV e inspeção visual. Rev Bras Ginecol Obstet. 2004;26(4):269-75.

4. Motta EV, Fonseca AM, Bagnoli VR, Ramos LO, Pinotti JA. Colpocitologia em ambulatório de ginecologia preventiva. Rev Assoc Med Bras (1992). 2001;47(4):302-10.

5. Brasil. Ministério da Saúde. Secretaria de Atenção à Saúde. Departamento de Atenção Básica. Controle dos cânceres do colo do útero e da mama. Brasília: Ministério da Saude; 2006.

6. Brasil. Secretaria da Saúde do Ceará (SES-CE). Metodologia de melhoria da qualidade em atenção à saúde: instrumento de avaliação e supervisão. Fortaleza: SESA/NUORG; 2002.

7. Polit DF, Beck CT, Hungler BP. Fundamentos de pesquisa em enfermagem: métodos, avaliação e utilização. 5a. ed. Porto Alegre: Artmed; 2004.

8. Brasil. Ministério da Saúde.Conselho Nacional de Saúde. Comissão Nacional de Ética em Pesquisa. Resolução No 196 de 10 de outubro de 1996. Diretrizes e normas regulamentadoras de pesquisa envolvendo seres humanos. Brasília: Ministério da Saúde; 1996.

9. Carvalho MLO, Furegato ARF. Exame ginecológico na perspectiva das usuárias de um serviço de saúde. Rev Eletrônica Enferm. 2001;3(1): [Internet] [citado em 2005 Jan 05]. Disponível em: http://www.fen.ufg.br/revista/ satisfatória, já que todas as lâminas seguidas foram lidas e tidas como adequadas pelo laboratório. Mas destacou-se que apesar das falhas observadas que colocaram as lâminas em risco para dessecamento, a presença de sangue e do material hipocelular não geraram lâminas insatisfatórias. Portanto, sugerimos que estudos sejam realizados com o objetivo de avaliar as recomendações desnecessárias ou excessivas à coleta. Neste ponto, preocupa a possibilidade de que as oportunidades de realização dos exames sejam perdidas.

De maneira geral, a logística dos materiais necessários à realização do exame foi considerada deficiente, assertiva que se faz com base nos episódios de suspensão de atendimento e de desperdício dos recursos. Tais eventos revelaram desarmonia no processo de organização e funcionamento dos serviços. É importante o conhecimento e o envolvimento do gestor local no que diz respeito à previsão e suprimento dos recursos necessários à realização da coleta, sob pena de ter a qualidade do serviço e a satisfação das usuárias comprometidas.

revista3_1/gineco.html

10. Sousa IGS. Percepções de mulheres com relação ao primeiro exame ginecológico- [monografia]. Fortaleza: UFC/ Graduação em Enfermagem; 2006.

11. Appling SE. Procedimentos em enfermagem. São Paulo: Reichhman \& Autores Editores; 2005. (Série Enfermagem Prática)

12. Moura ERF, Nogueira RA. Atuação de enfermeiras nas ações de controle do câncer de mama em oito unidades de saúde do Ceará, Brasil. Rev Bras Saúde Matern Infant. 2001;1(3):269-74.

13. Eduardo KGT, Américo CF, Ferreira ERM, Pinheiro AKB, Ximenes LB. Preparação da mulher para a realização do exame de Papanicolaou na perspectiva da qualidade. Acta Paul Enferm. 2007;20(1):44-8.

14. Duavy LM, Batista FLR, Jorge MSB, Santos JBF. A percepção da mulher sobre o exame preventivo do câncer cérvico-uterino: estudo de caso. Ciênc Saúde Coletiva. 2007;12(3):733-42.

15. Oliveri DP. O "ser doente": dimensão humana na formação do profissional da saúde. São Paulo: Moraes; 1985.

16. Brasil. Secretaria da Saúde do Ceará (SES-CE). Instituto de Prevenção do Câncer. Protocolo de condutas médicas do Instituto de Prevenção do Câncer. Fortaleza: SES-CE; 2006.

17. Buntinx F, Brouwers M. Relation between sampling device and detection of abnormality in cervical smears: a metaanalysis of randomised and quasi-randomised studies. BMJ. 1996;313(7068):1285-90. Comment in: BMJ. 1996;313(7068):1275-6. BMJ. 1997;314(7089):1277.

18. Tavares CM, Prado ML. Pesquisando a prevenção do câncer ginecológico em Santa Catarina. Texto \& Contexto Enferm. 2006;15(4):578-86.

19. Pessini AS, Silveira GPG. Câncer genital feminino. In: Duncan BB, Shmidt MI, Giugliani ERJ, organizador. Medicina ambulatorial: condutas de atenção primária baseadas em evidências. 3a. ed. Porto Alegre: Artmed; 2004. p. 471-9 